\title{
Coralline Hydroxyapatite Bone Graft in Non-Contained Defects: Case Report
}

\author{
Peter Vickers ${ }^{1}$, Gordon Slater ${ }^{2 *}$, Luke Mathen ${ }^{3}$ \\ ${ }^{1}$ BMD, BDS (Edinburgh) FDS, RCS (England), FRACDS CERT.OMS, Louisiana, USA \\ ${ }^{2}$ MBBS (UNSW) FRACS, FA, Ortho A, New South Head Rd, Double Bay NSW 2028, Australia \\ ${ }^{3}$ Bachelor of Biomedical Engineering/Commerce, The University of Sydney, Australia \\ *Corresponding Author: Gordon Slater, MBBS (UNSW) FRACS, FA, Ortho A, New South Head Rd, Double \\ Bay NSW 2028, Australia; Email: gordonjakll@gmail.com \\ Received Date: 09-09-2021; Accepted Date: 01-10-2021; Published Date: 08-10-2021 \\ Copyright $^{\odot} 2021$ by Slater G, et al. All rights reserved. This is an open access article distributed under the terms \\ of the Creative Commons Attribution License, which permits unrestricted use, distribution and reproduction in \\ any medium, provided the original author and source are credited.
}

\begin{abstract}
Substitute bone grafts are gaining popularity in orthopaedics and faciomaxillary surgery. There are numerous products that are available to clinicians currently on the market. Here, we present a case report of a large non-contained mandibular defect that was successfully treated with a Coralline Hydroxyapatite (CHA). This paper will discuss the need for CHA in dental bone defect repair, and it's effectiveness in the specific case study.
\end{abstract}

\section{Keywords}

Bone Grafting; Mandibular Defects; Regenerative Medicine; Orthobiologics

\section{Introduction}

Bone grafts primarily act as a scaffold, whereby new bone formation and wound healing can occur. The need for this stems from the need to fill defect sites that may have arisen due to surgery, trauma, infection, or congenital factors [1]. Failure to fill defect sites and tooth loss causes rapid resorption of alveolar bone from a lack of intraosseous stimulation, harming the functionality and form of facial structure [1]. Hydroxyapatite is commonly used as a graft 
material due to it being a constituent of inorganic bone tissue. It facilitates bone regeneration and stem cell proliferation, and becomes almost indistinguishable from bone after implantation [2]. Loss of skeletal mass in the face contributes to the appearance of aging in the face, and is also associated with various functional challenges [3].

\section{Case Report}

The following case outlines successful integration of coralline hydroxyapatite graft into the bone. These two images demonstrate respectively a large mandibular defect, before and after treatment with coralline hydroxyapatite. The patient was a 66-year-old woman, with an odontogenic cyst causing the mandibular defect (Fig. 1).

The defect healed well post-operatively without any complications. The latter image clearly shows a well-integrated graft, and a filled mandibular defect.

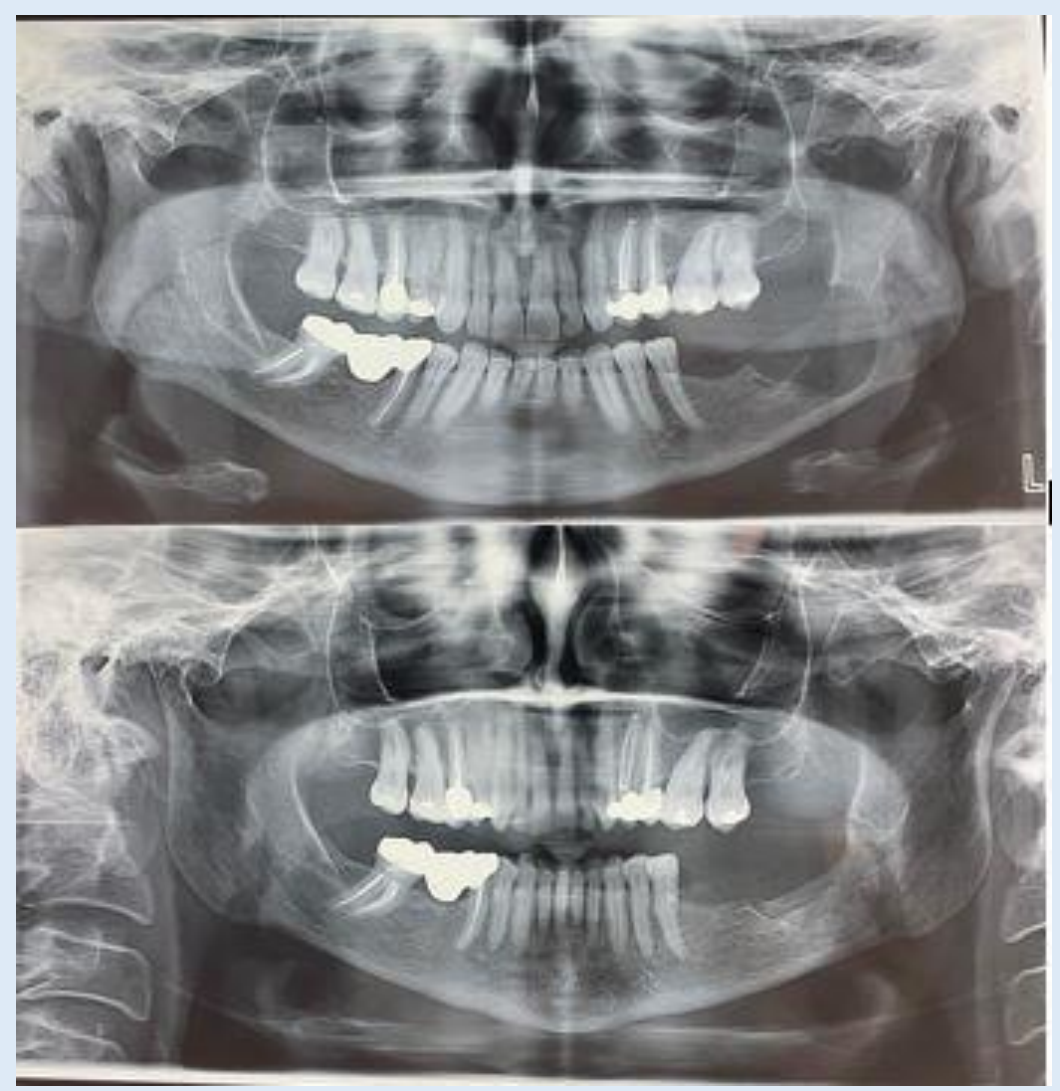

Figure 1: (A): Pre-operative image of mandibular defect; (B): 8-month post-operative image of Integrant GraftIT treated mandibular defect.

Vickers P | Volume 2; Issue 3 (2021) | JDHOR-2(3)-033 | Case Report

Citation: Slater G, et al. Coralline Hydroxyapatite Bone Graft in Non-Contained Defects: Case Report. J Dental Health Oral Res. 2021;2(3):1-6. 


\section{Discussion}

The need for bone grafting is increasing in society. Approximately 5-10\% of all bone defects have poor healing results, and as of 2016, over 2.2 million bone grafts were being performed each year [4]. Pneumatization (bone air spaces) results in a lack of mass in cancellous and cortical bone, resulting in instability, and a heightened likelihood of implant failure [5]. Nonautograft products are gaining in popularity as the issues of limited supply and donor site morbidity become increasingly problematic with increasing demand. Coraline hydroxyapatite (CHA) is manufactured from marine coral, a biomimetic approach given the trabecular structure of coral, resembling that of bone.

The mandibular defect presented in the above case is large, and could pose a significant functional and cosmetic challenge. Issues related to malocclusion and even proprioception can be the result of such defects. In the above case, the surgeon considers a whole variety of functionality, including chewing, swallowing and speech [3]. The CHA graft clearly restores bony contour. Long-term follow-up is necessary to assess the patient on cosmetic and functional factors.

It is also important to consider alternate graft treatment options for such a patient. Autologous materials represent a gold standard in the industry. Whilst they avoid donor wait lists and encourage bone ingrowth, they require two surgeries, and the resultant increased costs, inflammation, infection and scarring [6-8]. The size of the defect also makes donor site morbidity a key concern. The complications of donor site morbidity can often be more severe than the presenting pathology [9]. The difficulties of pathogen transmission with allografts and xenografts make natural coralline hydroxyapatite grafts a suitable solution [10].

As previously mentioned, a supportive structure such as a collagen membrane might provide utility for facilitating stability during bone graft ingrowth [11]. In this case, no membrane was used and optimal results were still observed. A membrane would have posed no additional benefit in the presented mandibular defect. However, there is still clinical benefits of membranes to prevent soft tissue in growth from interrupting osteogenesis by creating a protected tissue environment [12].

Integrant GraftIT allows population of osteoblasts within three months that will convert to woven bone over two years. Resorption of bone present in soft tissue will occur. Studies have demonstrated limited to no inflammatory reaction, superior cell adhesion, and osteoconductivity [13]. GraftIT's osteoconduction indicates that the graft acts as a scaffold for bone ingrowth and cell infiltration [1]. It is likely that better results would be seen if the graft were osteoinductive, meaning osteoprogenitor cells differentiate into osteoblasts and form new

Vickers P | Volume 2; Issue 3 (2021) | JDHOR-2(3)-033 | Case Report

Citation: Slater G, et al. Coralline Hydroxyapatite Bone Graft in Non-Contained Defects: Case Report.

J Dental Health Oral Res. 2021;2(3):1-6.

DOI: http://dx.doi.org/10.46889/JDHOR.2021.2302 
bone [9]. Despite this, good results in terms of vascularisation and cell penetration have been demonstrated, which is essential for osteogenesis [5]. Because of an inherent mechanical weakness, CHA is suited for low load maxillofacial applications [14].

The acquisition of coral is important to consider, and is subject to ethical and regulatory concerns. Coral from the Porite and Goniopora species are used given their anatomical similarities to human bone. After toxin screening and shaping, the calcium carbonate skeleton is converted to hydroxyapatite granules, where carbonate phases are decomposed, and organic materials removed [15]. A pure coralline HA powder is formed by reaction with ammonium phosphate which is used in the production of GraftIT [14]. Exploitation of marine ecosystems is an important consideration, given that corals contribute greatly to marine biodiversity. Harvesting must be done in moderation to preserve ecosystems and prevent extinction (Fig. 24) $[16]$.

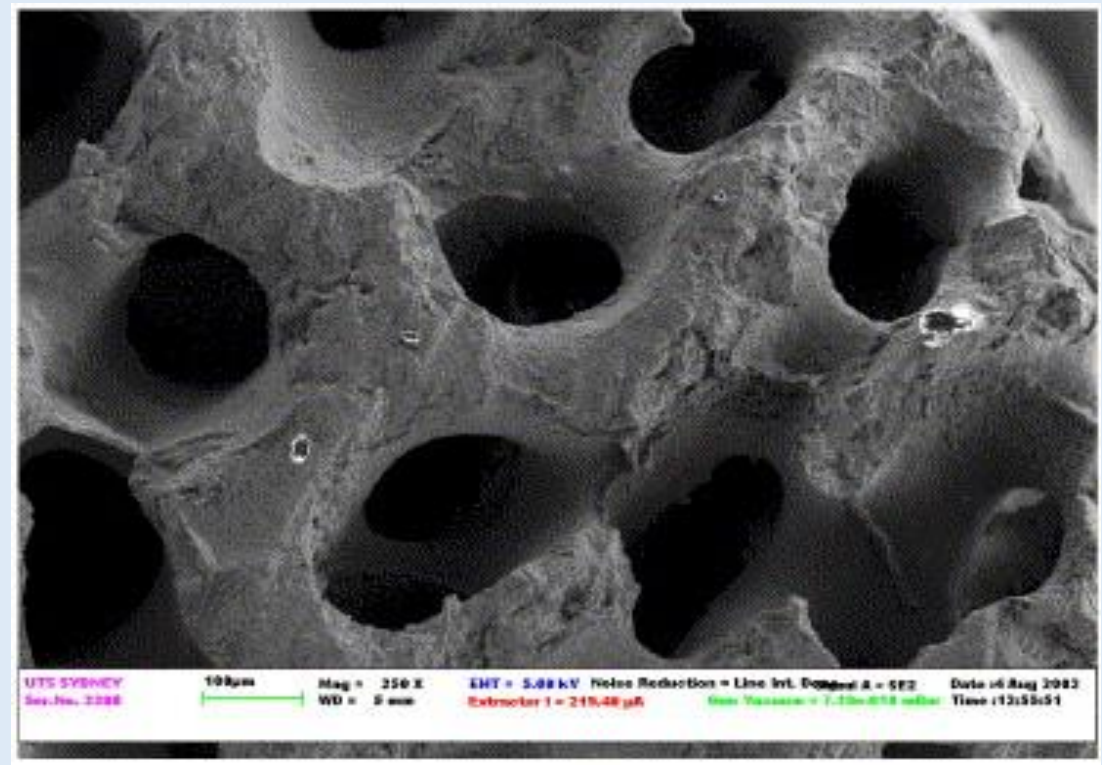

Figure 2: The trabecular structure of natural coral [6].
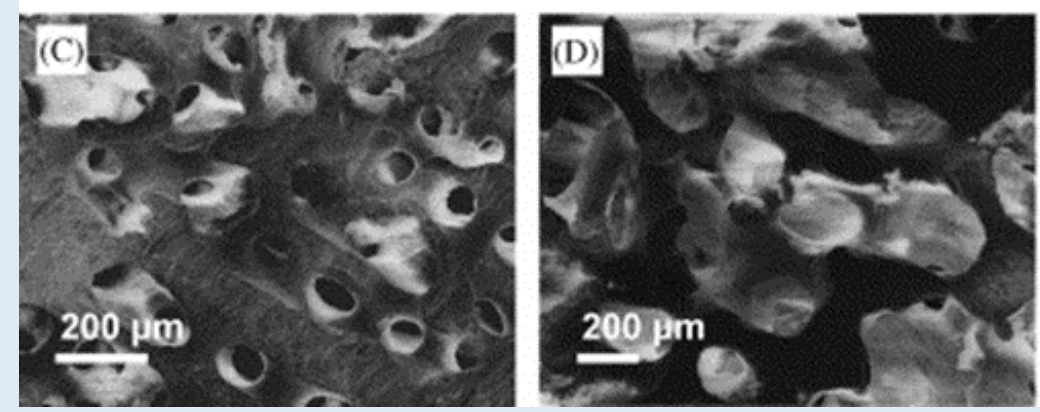

Figure 3: Microstructure of coralline hydroxyapatite bone scaffolds of c. $200 \mu \mathrm{m}$ pore size and d. $500 \mu \mathrm{m}$ pore size [7].

Vickers P | Volume 2; Issue 3 (2021) | JDHOR-2(3)-033 | Case Report

Citation: Slater G, et al. Coralline Hydroxyapatite Bone Graft in Non-Contained Defects: Case Report. J Dental Health Oral Res. 2021;2(3):1-6. 


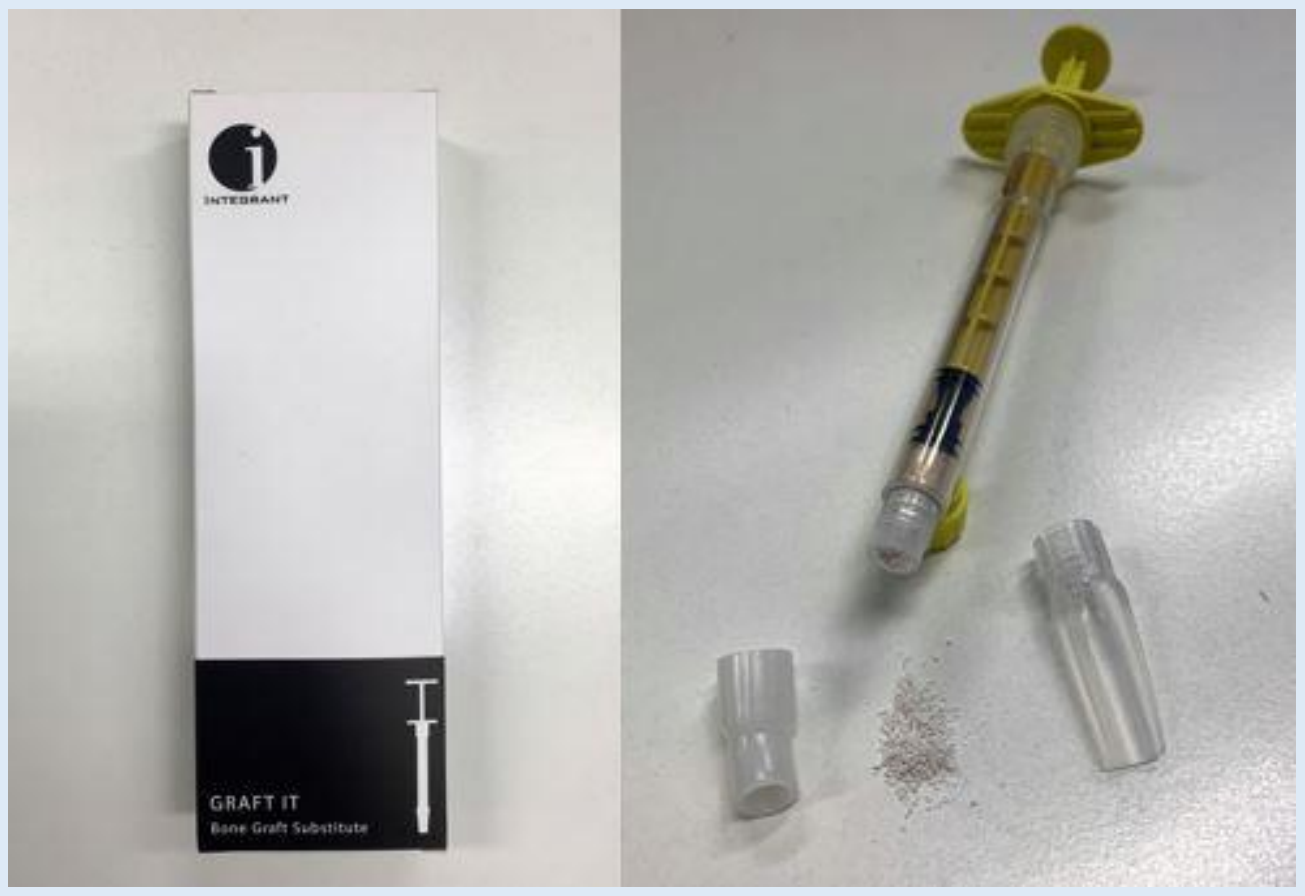

Figure 4: GraftIT bone graft substitute.

\section{Conclusion}

Coralline hydroxyapatite provided a successful solution for the grating of a large non-contained defect of the mandible. Grafting will increase in frequency with the aging population and the co-existing desire to maintain the function and cosmesis associated with having teeth. The use of synthetic and natural bone grafts will expand into the future due to inherent issues associated with autografts and allografts. Further research into the field is necessary to improve the mechanical loading capabilities of grafts, as well as osteoinductivity.

\section{Conflict of Interest}

Dr. Gordon Slater is medical Director of Integrant a medical Device Company.

\section{References}

1. Kumar P, Vinitha B, Fathima G. Bone grafts in dentistry. J Pharma Bioallied Sci. 2013;5(Suppl 1):S125.

2. Oliveira HL, Da Rosa WL, Cuevas-Suárez CE, Carreno NL, da Silva AF, Guim TN, et al. Histological evaluation of bone repair with hydroxyapatite: a systematic review. Calcified Tissue Int. 2017;101(4):34154.

3. Rana M, Warraich R, Kokemüller H, Lemound J, Essig H, Tavassol F, et al. Reconstruction of mandibular defects-clinical retrospective research over a 10-year period. Head and Neck Oncol. 2011;3(1):1-7.

Vickers P | Volume 2; Issue 3 (2021) | JDHOR-2(3)-033 | Case Report

Citation: Slater G, et al. Coralline Hydroxyapatite Bone Graft in Non-Contained Defects: Case Report.

J Dental Health Oral Res. 2021;2(3):1-6.

DOI: http://dx.doi.org/10.46889/JDHOR.2021.2302 
4. Dunstan C, Li JJ, Quach T, Roohaniesfahani S, Zreiqat H, Pivonka P, Saifzadeh S, Steck R. Efficacy of novel synthetic bone substitutes in the reconstruction of large segmental bone defects in sheep tibiae. Biomed Mat. 2016;11(1):015016.

5. Luo ZB, Zhang QB, Zhang ZQ, Chen D, Yan WX, Li KF, et al. Performance of coralline hydroxyapatite in sinus floor augmentation: a retrospective study. Clin Oral Invest. 2013;17(9):2003-10.

6. Ben-Nissan B, Milev A, Vago R. Morphology of sol-gel derived nano-coated coralline hydroxyapatite. Biomaterials. 2004;25(20):4971-5.

7. Mygind T, Stiehler M, Baatrup A, Li H, Zou X, Flyvbjerg A, et al. Mesenchymal stem cell ingrowth and differentiation on coralline hydroxyapatite scaffolds. Biomat. 2007;28(6):1036-47.

8. Haugen HJ, Lyngstadaas SP, Rossi F, Perale G. Bone grafts: which is the ideal biomaterial? J Clin Periodontol. 2019;46:92-102.

9. Henkel J, Woodruff MA, Epari DR, Steck R, Glatt V, Dickinson IC, et al. Bone regeneration based on tissue engineering conceptions-a $21^{\text {st }}$ century perspective. Bone Res. 2013;1(1):216-48.

10. RL SA. Bone tissue engineering: state of the art and future trends. Macromol Biosci. 2004;4:743-65.

11. Iorio-Siciliano V, Andreuccetti G, Blasi A, Matarasso M, Sculean A, Salvi GE. Clinical outcomes following regenerative therapy of non-contained intrabony defects using a deproteinized bovine bone mineral combined with either enamel matrix derivative or collagen membrane. J periodontol. 2014;85(10):1342-50.

12. Stevens MM. Biomaterials for bone materials that enhance bone regeneration have a wealth of potential. Bone. 2008;11(5):18-25.

13. Neto AS, Ferreira JM. Synthetic and marine-derived porous scaffolds for bone tissue engineering. Materials. 2018;11(9):1702.

14. Damien E, Revell PA. Coralline hydroxyapatite bone graft substitute: a review of experimental studies and biomedical applications. J Appl Biomat Biomech. 2004;2(2):65-73.

15. Sivakumar M, Kumar TS, Shantha KL, Rao KP. Development of hydroxyapatite derived from Indian coral. Biomaterials. 1996;17(17):1709-14.

16. Montero-Serra I, Linares C, García M, Pancaldi F, Frleta-Valić M, Ledoux JB, et al. Harvesting effects, recovery mechanisms, and management strategies for a long-lived and structural precious coral. PloS One. 2015;10(2):e0117250. 